DOI: $10.26730 / 1999-4125-2018-3-79-85$

УДК 66.06
РЕОЛОГИЧЕСКИЕ ИССЛЕДОВАНИЯ ВОДНЫХ РАСТВОРОВ ПОЛИМЕРОВ, ПРИМЕНЯЕМЫХ В КАЧЕСТВЕ ЗАГУСТИТЕЛЕЙ ГИДРАВЛИЧЕСКИХ ЖИДКОСТЕЙ

\title{
RHEOLOGICAL STUDIES OF POLYMER AQUEOUS SOLUTIONS USED AS THICKENERS OF HYDRAULIC FLUIDS
}

\author{
Черкасова Татьяна Григорьевна, \\ доктор химич. наук, професcop, e-mail: ctg.htnv@kuzstu.ru \\ Tatyana G. Cherkasova, Dr. Sc. (Chemistry), Professor, \\ Ахремкова Юлия Сергеевна, \\ аспирант, e-mail: ahremkova80@mail.ru \\ Yuliya S. Akhremkova, postgraduate student
}

Кузбасский государственный технический университет имени Т.Ф. Горбачева, 650000, Россия, г. Кемерово, ул. Весенняя, 28

T. F. Gorbachev Kuzbass State Technical University, 28, Vesennyaya St., Kemerovo, 650000, Russian Federation

\begin{abstract}
Аннотация: Проведен анализ литературы по классификации, составу и свойствам гидравлических жидкостей. В современных гидравлических системах в угольной отрасли применяют гидравлические жидкости типа НFА. Это водомасляные эмульсии или водные растворы химических соединений, с соответствующими присадками. Наиболее распространенными являются гидравлические жидкости на основе полимеров. В статье проведен комплексный анализ растворов полиэтиленгликолей (ПЭГ) различной молекулярной массы при разных температурах. Проведены испытания по определению кинематической вязкости систем «ПЭГ-дистиллированная вода» $и$ "ПЭГ- «жесткая» вода». На основании полученньхх данных проведены расчеты показателей, характеризующих вязкость. Определены характеристическая вязкость, константы Хаггинса и а для данных систем. Также показано влияние температуры и жесткости воды на состояние молекул ПЭГ в растворе. Сделаны предположения о поведении и структуре макромолекул полимеров в растворе. Исследования показали, что водные растворы высокомолекулярных полимеров более стабильны по сравнению с водными растворами низкомолекулярных полимеров. Стабильность высокомолекулярных соединений обусловлена прочными связями между мономерами полимерной цеепи и образованием водородных связей макромолекул полимера с молекулами воды.
\end{abstract}

Ключевые слова: Гидравлическая жидкость, добыча угля, водный раствор, полиэтиленгликоль, вязкость, макромолекула, полимеры, молекулярный вес.

Abstract: The literature on the classification, composition and properties of hydraulic fluids is presented. Hydraulic fluids type HFA are used in modern hydraulic systems in the coal industry. These are water-oil emulsions or aqueous solutions of chemical compounds with appropriate additives. The most common hydraulic fluids are based on polymers. The complex analysis of solutions in polyethylene glycols (PEG) of various molecular weights at different temperatures is carried out in the article. Tests have been conducted to determine the kinematic viscosity of the systems "PEG - distilled water" and "PEG - 'hard' water". The calculations of the parameters characterizing the viscosity were made on the basis of the obtained data. The inherent viscosity, $\alpha$ and Haggins constants have been defined for the given systems. The behavior and structure of macromolecules in aqueous solutions of different rigidity are described. The process of formation of equilibrium solutions of polymers is considered. Also, influence of water temperature and hardness on the state of PEG molecules in the solution is shown. The assumptions about the structure of macromolecules of polymers in solution are made. The studies have shown that aqueous solutions of high-molecular polymers are more stable than aqueous solutions of low-molecular polymers. Stability of high-molecular compounds is due to strong bonds between polymer chain monomers and the 
formation of hydrogen bonds of polymer macromolecules with water molecules.

Key words: Hydraulic fluid, coal mining, aqueous solution, polyethylene glycol, viscosity, macromolecule, polymers, molecular weight.

Рабочая жидкость в гидросистемах механизированного комплекса осуществляет роль рабочего тела. Она обеспечивает перенос энергии от одного узла системы к другому [1], и превращения этой энергии в полезную работу, используя для этого напорные потоки. Кроме того, она выполняет много важных функций.

Первой жидкостью для гидравлических систем была вода. Но в результате модернизации горнодобывающей отрасли Российской Федерации возникла необходимость в применении других жидкостей с соответствующими эксплуатационными характеристиками. Современная гидравлическая система механизированной крепи спроектирована так, чтобы можно было применять стабильные, нетоксичные трудновоспламеняемые рабочие жидкости типа HFA [2]. Это водомасляные эмульсии или водные растворы химических соединений [3], с соответствующими присадками. Очень важно правильно подобрать базовую основу для рабочей жидкости. Наиболее востребованными являются рабочие жидкости на основе органических полимеров

Рабочая жидкость в гидравлической системе движется с огромной скоростью. Стенки гибких и жестких трубопроводов создают препятствия для свободного движения жидкости. В связи с этим возникают гидравлические сопротивления, на преодоление которых затрачивается часть энергии потока (гидравлические потери). Установлено, что при введении водорастворимых полимеров с линейной структурой молекул наблюдается снижение гидравлического сопротивления [4]. Механизм влияния полимеров заключается в гашении турбулентных вихрей. Так как водные растворы некоторых полимеров обладают вязкими, смазывающими и упругими свойствами, то именно они используются для выражения эффекта Томса $[5,6]$ при турбулентном течении растворов полимеров.

Характерных особенностью растворов полимеров является вязкость. На молекулярном уровне вязкость полимерного раствора - это мера объема, который занимает разрыхленный или набухший молекулярный клубок вместе с захваченным растворителем [7]. В отличие от низкомолекулярных веществ, полимеры образуют растворы с очень высокой вязкостью. Известно, что полимеры образуют вязкие растворы уже при концентрации $0,5-$ $1,0 \%$ [8]. В литературных источниках описывается непостоянство вязкости при разных скоростях течения, зависимость от температуры и молекулярной массы. В гидросистеме механизированной крепи температура рабочей жидкости достигает 50 ${ }^{\circ} \mathrm{C}$. Поэтому необходимо подобрать такой комплекс полимеров, которые будут выдерживать перепады температур.

В качестве загустителей присадок в трудновоспламеняемых гидравлических жидкостях используют полимеры, способные образовывать истинные растворы $[9,10]$. Такие растворы характеризуются лиофильностью, самопроизвольностью образования, гомогенностью в определенных условиях и термодинамической устойчивостью. Для растворов полимеров наиболее часто встречается следующий механизм загущения. Изначально молекулы полимера попадают в молекулы растворителя. Но нужно отметить, что процессу растворения полимера предшествует процесс набухания. Время набухания может составлять от нескольких часов до нескольких суток (рис. 1). В результате взаимодействия между фрагментами полимерной цепи, макромолекулы полимера свёрнуты в плотные

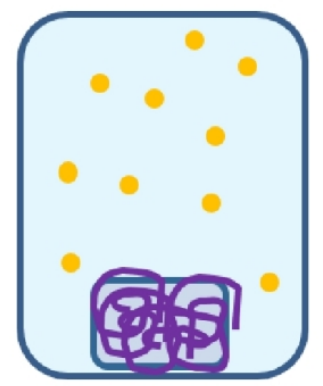

Помещение полимера в раствор

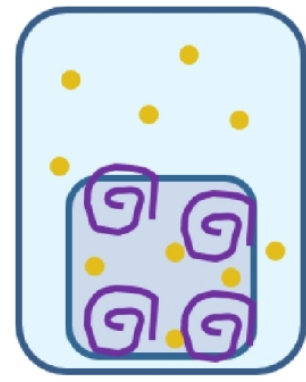

$$
\begin{gathered}
\text { Набухание } \\
\text { полимера }
\end{gathered}
$$
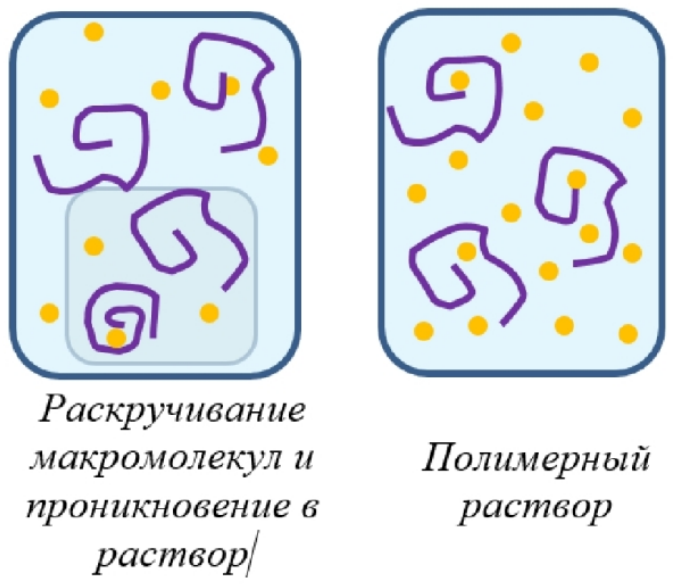

Полимерный

раствор

Рис. 1 Образование раствора полимера

Fig. 1 Formation of polymer solution 


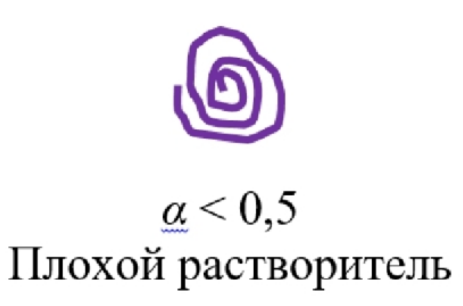

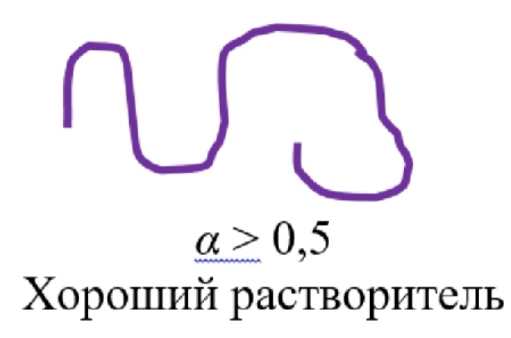

растворитель

Рис. 2 Состояние макромолекул в разных растворителях Fig. 2 State of macromolecules in different solvents

клубки. Попадая в воду, клубки немного раскручиваются за счет взаимодействия макромолекул полимера с молекулами воды, превращаясь в рыхлые ассоциаты. В результате макромолекула приобретает более линейную конфигурацию, подвижность молекул воды ограничивается, а вязкость раствора возрастает.

Макромолекула пропитана частицами воды так, что плотность ассоциатов примерно равна плотности чистой воды. За счет этого ассоциаты равномерно распределены в объёме воды. Мономерные участки макромолекул и частицы воды связаны силами межмолекулярного взаимодействия, вследствие чего полимерная цепь выполняет роль "каркаса" раствора, не позволяющего ему разрушаться под действием каких-либо сил, которым клубок подвергается в процессе сдвигового течения. Поэтому полимерные растворы обладают вязкими и упругими свойствами.

Важно установить концентрационный режим полимера, а именно определить при какой концентрации полимер придаст раствору необходимую вязкость. А также провести оценку качества растворителя для полимера. Для оценки концентрационной зависимости вязкости разбавленных растворов полимеров и оценки качества растворителя осуществляют по величинам характеристической вязкости и констант Хаггинса и $\alpha$ [11].

Характеристическая вязкость характеризует поведение молекул полимера в растворе. Она является мерой потерь энергии на трение макромолекул полимера о молекулы растворителя при их вращении и движении в растворе. Поэтому характеристическая вязкость зависит как от размеров макромолекул в растворе, так и от природы растворителя и температуры раствора. Чем меньше поверхности соприкосновения макромолекулы полимера и растворителя, тем меньше характеристическая вязкость. Характеристическая вязкость величина обратная концентрации.

Константа Хаггинса характеризует интенсивность взаимодействия в системе полимер - растворитель. Чем больше ее величина, чем хуже растворитель для данного полимера. Величина $K_{h}$ не зависит от молекулярной массы полимера и используется для оценки сродства между молекулами полимера и молекулами растворителя.
Константа $\alpha$ характеризует гибкость и свернутость макромолекул в растворе. Если $\alpha<0,5$, то макромолекула представляет собой плотно свернутый клубок, а соответственно неправильно подобран растворитель. При $\alpha=0,5$ макромолекула частично развернута, промежуточный растворитель. А при $\alpha>0,5$ макромолекула представляет собой развернутый клубок, то есть растворитель подобран правильно (рис. 2).

В настоящее время наиболее популярными являются рабочие жидкости для гидравлических систем на основе полиалкиленгликолей [12]. Поэтому целесообразным является испытание растворов именно этих полимеров. Объектом исследования являлась система полиэтиленгликоль - вода. Изучались четыре образца полиэтиленгликоля (ПЭГ) с разной молекулярной массой: ПЭГ-400, ПЭГ-1000, ПЭГ-9000 и ПЭГ-20000. Для исследуемых образцов определены значения кинематической вязкости при разных концентрациях растворов полимера при температурах: $20,30,40$ и $50{ }^{\circ} \mathrm{C}$. В условиях шахты рабочая жидкость готовится на основе воды различного класса чистоты и жесткости. Для эксперимента брали два типа воды: дистиллированную и воду со значением жесткости 12,8 мг-экв/л (жесткая вода). Испытания проводились согласно ГОСТ 33-2016 и ГОСТ 18249-72 [13-15]. Навески полимеров четырех концентраций $\left(0,1 ; 0,25 ; 0,5 ; 1,0\right.$ г на 100 cm$\left.^{3}\right)$ взвешивали на аналитических весах GR-200 с точностью $\pm 6 \cdot 10^{-4}$ г и растворяли в мерной колбе объемом $100 \mathrm{~cm}^{3}$. Растворы выдерживали на водяной бане для полного растворения полимера. Затем проводили измерение кинематической вязкости с помощью вискозиметра ВПЖ-2 с диаметром капилляра $d=0,34$ мм.

На основании полученных результатов рассчитывали приведенную вязкость $\eta_{\text {пр }}$ :

$$
\eta_{\text {пр }}=\frac{\eta_{\mathrm{p}-\mathrm{pa}}-\eta_{\mathrm{p}-л я}}{\eta_{\mathrm{p}-л я} \cdot \mathrm{C}}=\frac{\eta_{\text {уд }}}{\mathrm{C}}
$$

и строили график зависимости приведенной вязкости от концентрации растворов. Из этого графика графически [16] определяли значения характеристической вязкости [ๆ] и константы $\alpha$, как тангенс угла наклона. Константу Хаггинса $K_{h}$ рассчитывали, используя уравнение Хаггинса (2): 
Таблица. Зависимость характеристической вязкости от температуры

Table. Dependence of the inherent viscosity on temperature

\begin{tabular}{|c|c|c|c|c|}
\hline $\begin{array}{c}\text { Наименование по- } \\
\text { лимера }\end{array}$ & \multicolumn{4}{|c|}{ Характеристическая вязкость растворов ПЭГ, дл/г } \\
\cline { 2 - 5 } & $20^{\circ} \mathrm{C}$ & $30{ }^{\circ} \mathrm{C}$ & $40{ }^{\circ} \mathrm{C}$ & $50{ }^{\circ} \mathrm{C}$ \\
\hline \multicolumn{5}{|c|}{ Водные растворы на основе дистиллированной воды } \\
\hline ПЭГ-400 & 0,020 & 0,027 & 0,030 & 0,028 \\
\hline ПЭГ-1000 & 0,052 & 0,049 & 0,049 & 0,051 \\
\hline ПЭГ-9000 & 0,261 & 0,254 & 0,229 & 0,212 \\
\hline ПЭГ-20000 & 0,384 & 0,368 & 0,354 & 0,347 \\
\hline \multicolumn{5}{|c|}{ Водные растворы на основе «жесткой» воды } \\
\hline ПЭГ-400 & 0,033 & 0,030 & 0,028 & 0,027 \\
\hline ПЭГ-1000 & 0,048 & 0,049 & 0,052 & 0,047 \\
\hline ПЭГ-9000 & 0,221 & 0,198 & 0,187 & 0,169 \\
\hline ПЭГ-20000 & 0,196 & 0,172 & 0,161 & 0,142 \\
\hline
\end{tabular}

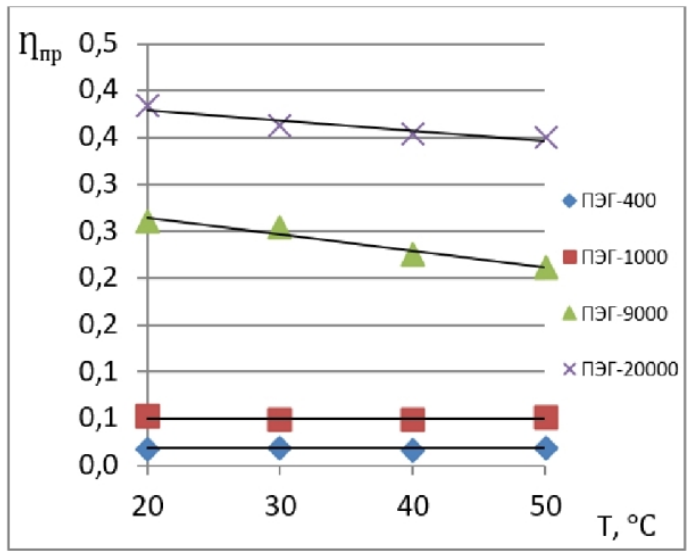

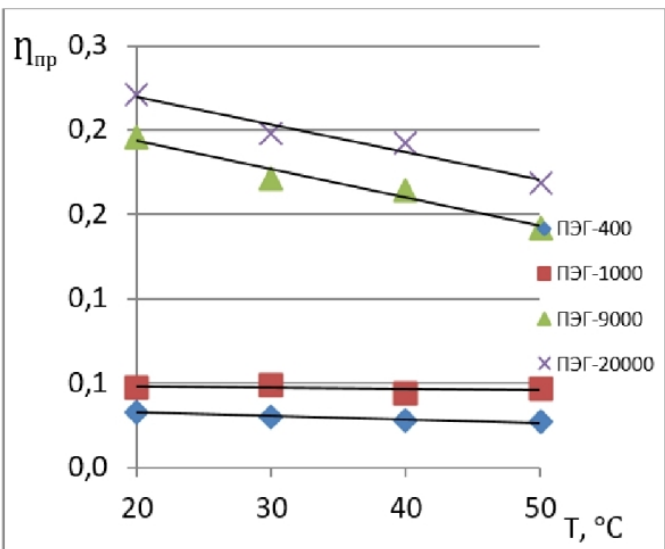

6

Рис. 3. Зависимость характеристической вязкости от температуры для систем: а) ПЭГ-дистиллированная вода; б) ПЭГ- «жесткая»вода

Fig. 3. Dependence of the inherent viscosity on temperature for systems: a) PEG - distilled water; b) PEG - 'hard' water

$$
K_{h}=\frac{\operatorname{tg}(\alpha)}{[\eta]}
$$

где $\operatorname{tg}(\alpha)$ - тангенс угла наклона;

[П] - характеристическая вязкость.

Результаты полученных значений характеристических вязкостей приведены в таблице, представленной в таблице.

Анализ полученных данных показал, что в системах низкомолекулярных ПЭГ - дистиллированная вода характеристическая вязкость с ростом температуры незначительно увеличивается, а для высокомолекулярных ПЭГ заметно уменьшается (рис. 3). Так происходит потому, что при повышении температуры увеличивается вращение и движение макромолекул и, чем больше размер макромолекулы, тем больше энергии тратится на ее вращение. Для всех образцов систем ПЭГ - «жесткая» вода с ростом температуры характеристическая вязкость уменьшается. В этих случаях в связи с наличием катионов и анионов, характеризующих жесткой воды, увеличивается мера неупорядоченности системы и соответственно вращение и движение молекул.

Для систем «ПЭГ - дистиллированная вода» величина $\alpha$ принимает значения больше 0,5 , что свидетельствует о том, что макромолекулы представляют собой развернутый клубок. Следовательно, растворитель подобран правильно. Для систем «ПЭГ - «жесткая вода» значения константы ниже 0,5. Примеси воды значительно ухудшают качество, и макромолекулы ПЭГ в растворе приобретают конфигурации клубка, приближаясь к конформации плотных глобул. Наблюдается увеличение значения константы $\alpha$ при увеличении температуры до $40^{\circ} \mathrm{C}$ из-за увеличения подвижности молекул воды и макромолекул. При температуре до $50^{\circ} \mathrm{C}$ значения величины $\alpha$ уменьшаются (рис. 4). 


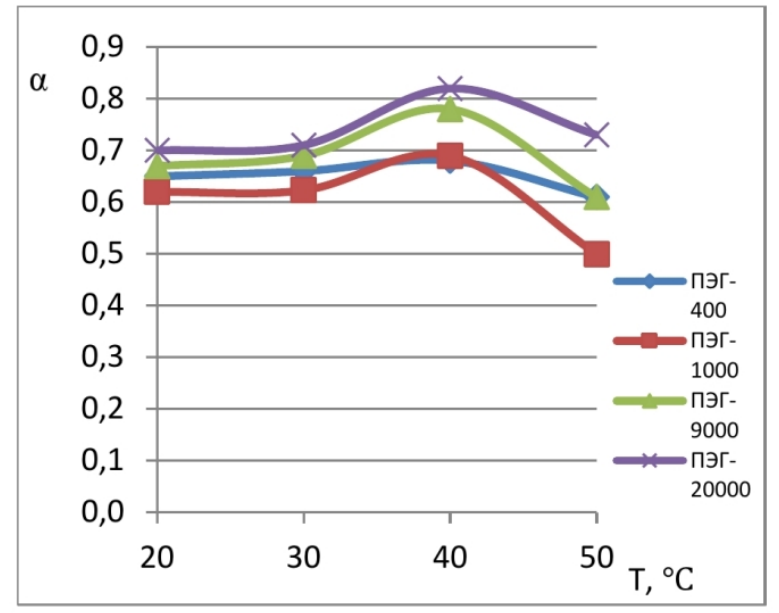

$a$

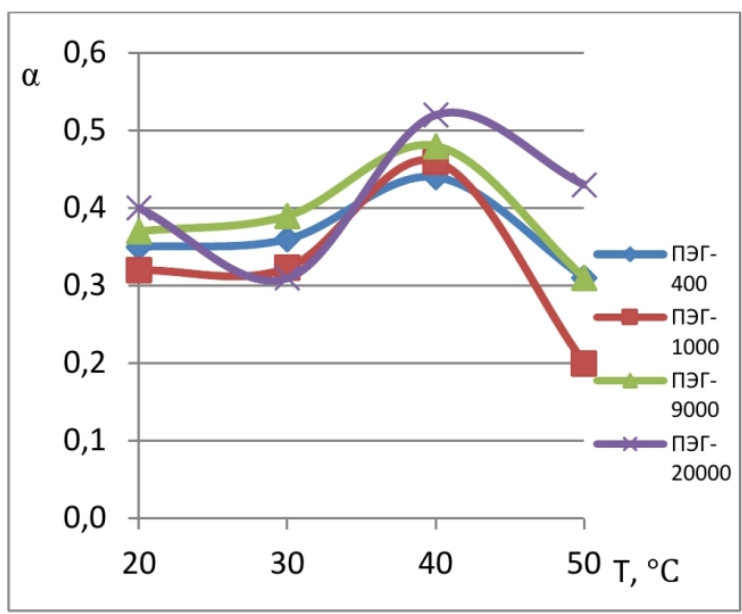

6

Рис. 4. Зависимость константы а от температуры для систем:

а) ПЭГ-дистиллированная вода; б) ПЭГ- «жесткая» вода

Fig. 4. Dependence of the constant $\alpha$ on temperature for systems:

a) PEG-distilled water; b) PEG - "hard" water

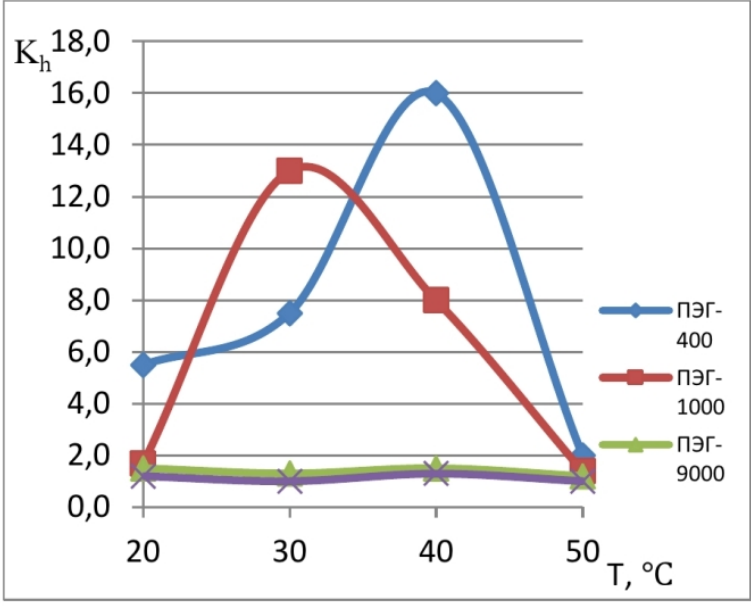

$a$

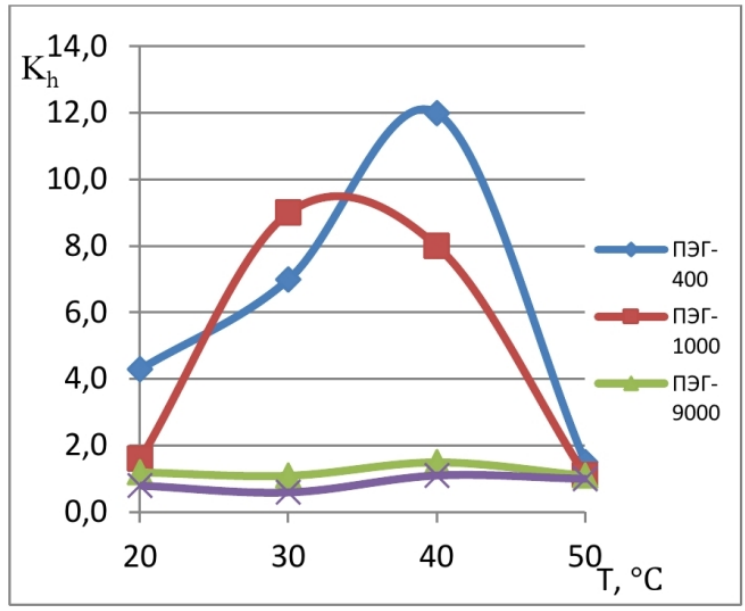

6

Рис. 5. Зависимость константы Хаггинса $K_{h}$ от температуры для систем:

a) ПЭГ-дистиллированная вода; б) ПЭГ- «жесткая» вода

Fig. 5. Dependence of the Haggins' constant $K_{h}$ on temperature for systems: a) PEG-distilled water; b) PEG - "hard" water

Это объясняется разрывом водородных связей и ослаблением влияние молекул воды на состояние макромолекул.

Проанализируем, что происходит с константой Хаггинса $K_{h}$ (рис.5). Согласно полученным данным сила взаимодействия между макромолекулами полимера и молекулами воды сильно зависит от температуры. Для низкомолекулярных ПЭГ при 30-40 ${ }^{\circ} \mathrm{C}$ наблюдается увеличение константы Хаггинса, а для высокомолекулярных ПЭГ значительных изменений константы Хаггинса с увеличением температуры не наблюдается. Это говорит о том, что взаимодействие макромолекул с молекулами воды в системах высокомолекулярных полимеров интенсивнее, для систем низкомолекулярных полимеров.

При выборе полимеров для получения гидравлических жидкостей необходимо понимать, что макромолекулы высокомолекулярных ПЭГ образуют более стабильные растворы за счет сил межмолекулярного взаимодействия и водородных связей с молекулами воды. Макромолекулы полимера образуют вязкие стабильные водные растворы, которые сохраняют свои свойства при высоких температурах. Качество воды также влияет на свойства рабочей жидкости для гидравлических систем механизированной крепи. Поэтому необходимо проводить надлежащую водоподготовку для получения качественного продукта. 


\section{СПИСОК ЛИТЕРАТУРЫ}

1. Папок К.К. Словарь по топливам, маслам, смазкам, присадкам и специальным жидкостям / К.К. Папок, Н.А. Рогозин. - М.: Химия, 1975. - 392.

2. Сазанов И.И. Гидравлика. Конспект лекций. Учебное пособие. - М.: ИЦ МГТУ Станкин, 2004. 292 c.

3. Birdi K.S. Surface Chemistry and Geochemistry of Hydraulic Fracturing: CRC Press, Taylor \& Francis Group, LLC, 2017. - p.194.

4. Белоусов Ю.П. Противотурбулентные присадки для углеводородных жидкостей. - Новосибирск.: Наука, 1986. - 177 c.

5. Fan R. J. Chemistry and Technology of Surfactants. - Blackwell Publishing Ltd, 2006. - p.316.

6. Чичканов С.В. Эффект Томса перспективные области применения / С.В. Чичканов, В.А. Мягченков // Вестник Казанского Технологического Университета. №: 2-2003. С. 314-329.

7. Гаварикер В.Р. Полимеры / В.Р. Гаварикер, Н.В. Висванатхан, Дж. Шридхар; пер. с англ.; под ред. В.А. Кабанова. - М.: Наука, 1990. - 396 с.

8. Максакова Л.А. Полимерные материалы и их применение. Учебное пособие / Л.А. Максакова, О.Ж. Аюрова. - Улан-Удэ: Изд. ВСГТУ. 2004. - 178 с.

9. Rudnick L.R. Synthetics, Mineral Oils, and Bio-Based Lubricants: Chemistry and Technology 2nd ed. CRC Press, Taylor \& Francis Group, 2013. - p. 1008. $-144 \mathrm{c}$.

10.Николаев А.Ф. Водорастворимые полимеры / А.Ф. Николаев, Г.И. Охременко. - Л.: Химия, 1979.

11.Рафиков С.Р. Введение в физико-химию растворов полимеров / С.Р. Рафиков, В.П. Будтов, Ю.Б. Монаков. - М.: Наука, 1978. - 328 с.

12. Дымент О.Н. Гликоли и другие производные окисей этилена и пропилена / О.Н. Дымент, К.С. Казанский, А.М. Мирошников / под ред. О.Н. Дымента. - М.: Химия, 1976. - 376 с.

13.Яновский Л.С. Основы химмотологии. - М.: Берлин: Директ-Медиа, 2016. - 482 с.

14. Totten G.E. Bench Testing of Industrial Fluid Lubrication and Wear Properties Used in Machinery Applications. - ASTM, 2001. - p.338.

15.Хуснуллин Р.Р. Композиционные составы для снижения гидравлического сопротивления в системах трубопроводного сбора и транспорта продукции нефтяных скважин: дис. канд. тех. наук: 02.00.13 / КНИТУ. - Казань, 2015. - 149 с.

16.Сафронов С.М. Нелинейная экстраполяция концентрационных зависимостей вязкости и структура растворов полимеров: автореф. дис. канд. хим. наук: 02.00.04 / С.М. Сафронов; Томск. гос. ун-т. - Томск, 2004. -24 c.

\section{REFERENCES}

1. Papok K.K. Slovar' po toplivam, maslam, smazkam, prisadkam i spetsial'nym zhidkostyam. - M.: Khimiya, 1975. 392 s. (rus)

2. Sazanov I.I. Gidravlika. Konspekt lekcij. Uchebnoe posobie. - M.: IC MGTU Stankin, $2004-292$ s. (rus)

3. Birdi K.S. Surface Chemistry and Geochemistry of Hydraulic Fracturing: CRC Press, Taylor \& Francis Group, LLC, 2017. - p.194.

4. Belousov, Y.U. Protivoturbulentnyye prisadki dlya uglevodorodnykh zhidkostey. - Novosibirsk.: Nauka, 1986. - 177 s. (rus)

5. Fan R.J. Chemistry and Technology of Surfactants. - Blackwell Publishing Ltd, 2006. - p.316

6. Chichkanov, S.V. Effekt Tomsa perspektivnyye oblasti primeneniya / S.V. Chichkanov, V.A. Myagchenkov // Vestnik Kazanskogo Tekhnologicheskogo Universiteta. №: 2-2003. S. 314-329. (rus)

7. Gavariker V.R. Polimery / V.R. Gavariker, N.V. Visvanatkhan, Dzh. Shridkhar; per. s angl.; pod red. V. A. Kabanova. - M.: Nauka,1990. - 396 s. (rus)

8. Maksakova, L.A. Polimernyye materialy i ikh primeneniye. Uchebnoye posobiye / L. A. Maksakova, O.Zh. Ayurova. - Ulan-Ude: Izd. VSGTU. 2004. - 178 s. (rus)

9. Rudnick L.R. Synthetics, Mineral Oils, and Bio-Based Lubricants: Chemistry and Technology 2nd ed. CRC Press, Taylor \& Francis Group, 2013. - p. 1008.

10.Nikolayev, A.F. Vodorastvorimyye polimery / A.F. Nikolayev, G.I. Okhremenko. - L.: Khimiya, 1979. 144 s. (rus)

11.Rafikov, S.R. Vvedeniye v fiziko-khimiyu rastvorov polimerov / S.R. Rafikov, V.P. Budtov, Yu.B. Monakov. - M.: Nauka, 1978. - 328 s. (rus)

12.Dyment, O.N. Glikoli i drugiye proizvodnyye okisey etilena i propilena / O.N. Dyment, K.S. Kazanskiy, 
A.M. Miroshnikov / pod red. O. N. Dymenta. - M.: Khimiya, 1976. - 376 s. (rus)

13.Yanovskij L. S. Osnovy himmotologii. - M.: Berlin: Direkt-Media, 2016. - 482 s. (rus)

14. Totten G.E. Bench Testing of Industrial Fluid Lubrication and Wear Properties Used in Machinery Applications. - ASTM, 2001. - p.338.

15.Husnullin R.R. Kompozicionnye sostavy dlya snizheniya gidravlicheskogo soprotivleniya v sistemah truboprovodnogo sbora i transporta produkcii neftyanyh skvazhin: dis. kand. tekh. nauk: 02.00.13 / KNITU. Kazan', 2015. - 149 s. (rus)

16. Safronov, S.M. Nelineynaya ekstrapolyatsiya kontsentratsionnykh zavisimostey vyazkosti i struktura rastvorov polimerov: avtoref.dis. kand. khim. nauk: 02.00.04 / S.M. Safronov; Tomsk. gos. un-t. - Tomsk, 2004. -24 s. (rus) 